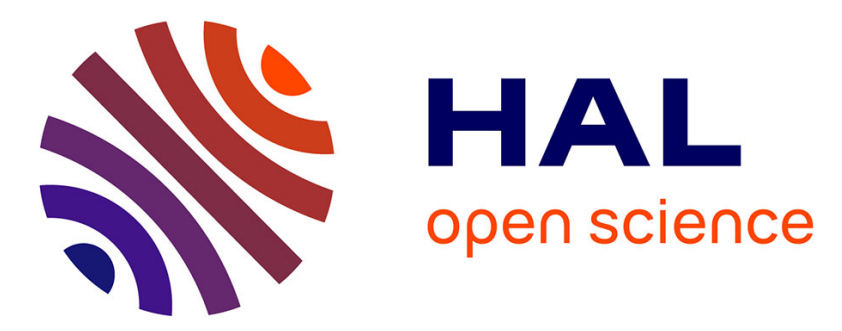

\title{
Impact on Energy Saving of Active Phase Count Control to a DC/DC Converter in a DC Micro Grid
}

Margot Gaetani-Liseo, Corinne Alonso, Lionel Séguier, Bruno Jammes

\section{To cite this version:}

Margot Gaetani-Liseo, Corinne Alonso, Lionel Séguier, Bruno Jammes. Impact on Energy Saving of Active Phase Count Control to a DC/DC Converter in a DC Micro Grid. 7th International Conference on Renouvable Energy Research and Applications (ICRERA 2018), IEEE, Oct 2018, Paris, France. 10.1109/ICRERA.2018.8566846 . hal-01963498

\section{HAL Id: hal-01963498 \\ https://hal.laas.fr/hal-01963498}

Submitted on 8 Jan 2019

HAL is a multi-disciplinary open access archive for the deposit and dissemination of scientific research documents, whether they are published or not. The documents may come from teaching and research institutions in France or abroad, or from public or private research centers.
L'archive ouverte pluridisciplinaire HAL, est destinée au dépôt et à la diffusion de documents scientifiques de niveau recherche, publiés ou non, émanant des établissements d'enseignement et de recherche français ou étrangers, des laboratoires publics ou privés. 


\title{
Impact on energy saving of active phase count control to a DC/DC converter in a DC micro grid
}

\author{
M. Gaetani-Liseo*†, C. Alonso*†, L. Seguier* and B. Jammes*† \\ ${ }^{*}$ LAAS-CNRS \\ †University Paul SABATIER - TOULOUSE 3 \\ Toulouse, FRANCE \\ mgaetani@laas.fr, alonsoc@laas.fr, lseguier@laas.fr, jammes@laas.fr
}

\begin{abstract}
This paper proposes to analyze the impact of active phase count control in DC/DC multi-phase bi-directional interleaved converter dedicated to energy storage system in low voltage DC micro grid for building integrated photovoltaic application. We focus our interest on the energy saved with an adaptive phase count control for real working conditions. To validate our approach a long term analysis was done based on a several years database of photovoltaic production and consumption power profile recorded in our laboratory building. To estimate the impact of our adaptive phase count control we built a model of converter efficiency for a large scale of operating points. Its parameters were identified through experimental measurements made on a bi-phase DC/DC bidirectional converter developed in LAAS-CNRS. Pertinence of APC control is estimated for 5 years simulation process and different load profiles. Results obtained in case of lightning network load profile, show that the energy lost without adaptive phase count control correspond to $4.22 \%$ of the energy exchange, against $3.72 \%$ with adaptive phase count control. This result correspond to a decrease of looses of $12 \%$. In order to study the impacts on a long term analyze we choose to discuss these results regarding the energy saved with adaptive phase count control. To complete our work we propose a comparative analysis with two different load profiles with details by month and days.

Index Terms-Adaptive Phase Count control; Interleaved Synchronous Buck Converter; bidirectional; DC/DC; multi-phase; efficiency; LVDC MG
\end{abstract}

\section{INTRODUCTION}

The deployment of decentralized Low Voltage DC MicroGrid (LVDC-MG) in building, with high penetration of renewable energy sources and Energy Storage Systems (ESS) involved high energy-efficient DC voltage conversion to be competitive compared to AC electrical networks. To achieve this aim, researches on advanced and efficient power architecture are needed. One of the solution is to use multi-phase structures working in interleaved control mode. Within this context, we propose a bi-phase Interleaved Synchronous Buck Converter (ISBC) as an interface between ESS and LVDC-MG in order to manage ESS charge and discharge. This ISBC is able to work with only one phase active (noted single phase mode) or with its two phases in interleaved control mode (noted bi-phase mode). The switch between single phase to biphase mode is managed by Active Phase Count control (APC control) and ensure an optimal ISBC efficiency. In this paper we analyze the potential benefits using APC control compared to a simple interleaved mode, in particular regarding the quantity of saved energy in our system, thanks to a 5 years data sets of PV power production and load power profiles: lighting network demand and electrical outlets demand, considered the typical load which could be supplying by LVDC-MG in building application [1]-[3].

In section II, we detail the power profiles chosen for the study and we present the LVDC-MG simulation process.

In section III, we described the ISBC made in LAAS-CNRS, its associated power looses model and the APC control adapted to this structure.

In the last section, we discuss the results obtained with different time horizons and load power profiles.

\section{THE LVDC-MG}

\section{A. Power profiles}

In order to analyze the impact of APC control on LVDCMG efficiency, we use 5 years data sets from ADREAM BiPV database [4], with a one minute time step. We select two different load power profiles: lighting and electrical outlets (PC, printers, office devices, ...). The load profiles are normalized to $1 \mathrm{~kW}$ to match with the nominal power of the PV and the nominal power of the ISBC developed and dedicated to our DC micro-grid [5].

Fig. 1 shows examples of PV production data and the scaled load power data, for a cloudy day. The power balance $\left(\mathrm{P}_{\mathrm{BAL}}\right)$ is the difference between the PV production $\left(\mathrm{P}_{\mathrm{PV}}\right)$ and the load consumption $\left(\mathrm{P}_{\mathrm{LOAD}}\right)$. $\mathrm{P}_{\mathrm{BAL}}$ is positive when the $\mathrm{DC}$ bus is overcharged and negative when the bus is overloaded, respectively our ISBC works as a buck to charge the ESS if its maximum voltage isn't reached and as a boost when ESS is discharging. These profiles put in evidence that the range of $\mathrm{P}_{\mathrm{BAL}}$ is wide, which is mainly due to the intermittence of PV source. Therefore, in order to reduce the power lost during the energy transfer to/from the battery, it is important that the converter provides a high efficiency in a wide power range.

\section{B. $L V D C-M G$ simulation}

As already written, our work is based on the LVDCMG created in LAAS-CNRS and described in [5]. For this study, we only consider the $\mathrm{OPzV}$ batteries and its associated charger/discharger. LVDC-MG operating conditions are given in table I. 


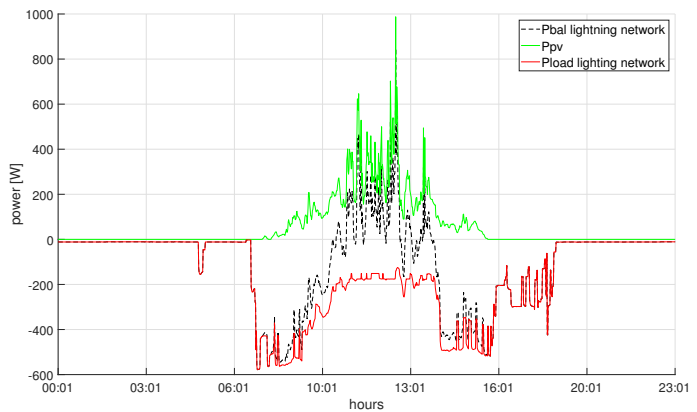

(a) lighting power profile

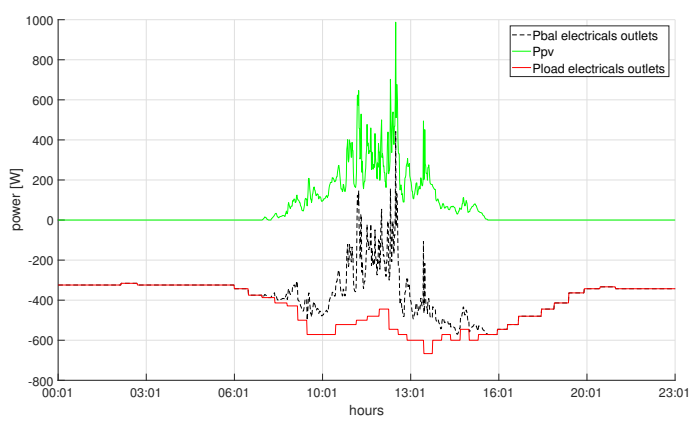

(b) electrical outlets power profile profile

Fig. 1. Power profiles of lighting and electrical outlets

TABLE I

LVDC-MG OPERATING CONDITIONS

\begin{tabular}{|c|c|c|c|}
\hline \multicolumn{3}{|c|}{ ESS } & Voltage DC bus \\
\hline SoC $[\%]$ & $V_{E S S} \quad[\mathrm{~V}]$ & $I_{E S S} \quad[\mathrm{~A}]$ & $V_{B U S} \quad[\mathrm{~V}]$ \\
\hline 10 to 90 & 32 to 43 & -25 to 25 & 54 \\
\hline
\end{tabular}

(a) according to $\mathrm{C}$-rate from manufacturer

$\mathrm{V}_{\mathrm{ESS}}$ and $\mathrm{I}_{\mathrm{ESS}}$ represent the ESS voltage and ESS current respectively. The DC bus voltage $\left(\mathrm{V}_{\mathrm{BUS}}\right)$ is regulated to $54 \mathrm{~V}$ during battery charging or discharging, as explained in [5]. $\mathrm{I}_{\mathrm{ESS}}$ is negative or positive according to the ESS operating mode.

The block diagram presented in fig. 2 illustrates how the models are combined to simulate power exchanges between the DC bus and the ESS. $P_{\mathrm{ESS}} *(\mathrm{t})$ represents the power balance after considering the battery state of charge $(\mathrm{SoC})$ and the current (C-rate) limits given in the data-sheet (bloc 1 on fig. 2). The second bloc of the bloc diagram corresponds to the battery voltage models. In first approach, we used a simplified version of Shepherd model [6]-[8] commonly used in building and sustainable applications [9]. We consider the batteries temperature constant. In these working conditions, the battery model is a voltage source $\left(\mathrm{V}_{\mathrm{OC}}\right)$ which is a linear function of battery SoC, associated to a constant serial resistor $\mathrm{R}_{\mathrm{ESS}}$. Several tests, with different values of constant current was performed on a battery, in order to identify the model parameters. The performances of our model was validated for a dynamic current profile. The current steps was arbitrary chosen inside $\mathrm{I}_{\mathrm{ESS}}$ range and the step duration was fixed to one minute, acording to the ADREAM database time step. In such conditions the relative error between experimental and simulated values of the battery voltage is less than $6 \%$. The third bloc of the bloc diagram is the converter efficiency model $(\eta(t))$. It is a function of the power delivered by/to the battery and the battery voltage. More details about this model are given in section III.

\section{Multi-Phase Synchronous DC/DC CONVERTER}

\section{A. Interleaved mode and APC control}

Compared to a classical structure, an ISBC allows to reduce thermal constraints, input and output current ripples and so allows to achieve optimal conversion and power transfer [10][14]. Even without APC control, this architecture is commonly used in PV and ESS applications [15]-[17]. By adapting the number of phase, the APC control theoretically implies a reduction of components losses, and thus an increase of the converter efficiency [18], [19]. In [20], a look-up table depending on input and output voltages of the converter is proposed to implemented the APC control. This paper concluded that the gain of PV energy transferred to the load was $2.9 \%$ higher than a classical structure, and that the lookup table method was a good compromise between feasibility, speed and reliability.

\section{B. Converter efficiency model}

An experimental study was done on a ISBC realized in LAAS-CNRS [5] in order to evaluate and model its converter efficiency and to define the optimal conditions in order to modify the number of active phases. By disabling or enabling the PWM outputs of the micro-controller embedded in the converter, we can activate each phase separately or the two phases in interleaved mode. For a fixed value of $\mathrm{V}_{\text {BUS }}$, the efficiency of the converter was measured for different values of $\mathrm{V}_{\mathrm{ESS}}$ and the power exchanged with the DC bus. Measures was made thanks to an automatized test bench developed in LAAS-CNRS. Fig. 3 shows the ISBC efficiency data in the four different configurations : in buck (battery are charging), in boost (battery are discharging) for single phase mode or bi-phase interleaved mode. Fig. 3 confirms that the maximum efficiency $(97.8 \%)$ was achieved when the two phases of the ISBC are activated.

The fig. 4 presents a focus on the ISBC efficiency measurements for ESS charging at $\mathrm{V}_{\text {ESS }}$ equal to $32 \mathrm{~V}$. These curves confirm that ISBC efficiency is improve by using single phase mode when the power delivered by the battery is less than $180 \mathrm{~W}$, beyond that the bi-phase mode is more efficient. By analyzing all the tests carried out, we can define a $\mathrm{I}_{\mathrm{ESS}} / \mathrm{V}_{\mathrm{ESS}}$ table that gives the optimal number of active phases, regarding the efficiency, for a large scale of operating points. According to the fig. 4, we can estimated that APC control can improve efficiency until $5 \%$ at low power working conditions.

To evaluate the impacts of an APC control in LVDCMG context, we studied the losses when the ISBC works all the time in interleaved mode without APC control or with 


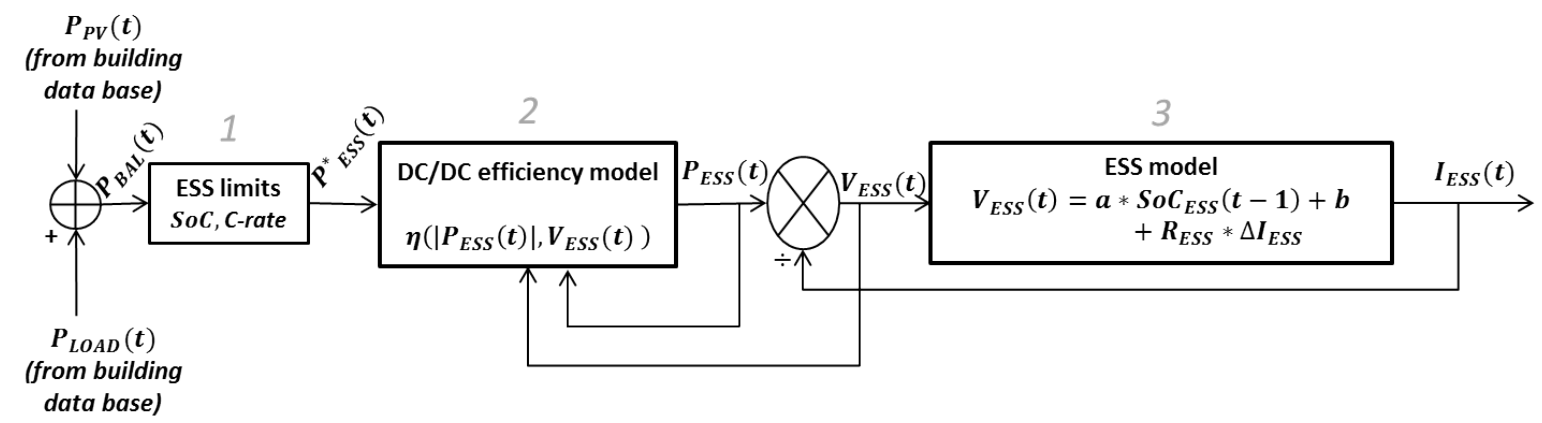

Fig. 2. Block diagram of the develop methodology for simulate power flow between batteries and LVDC network

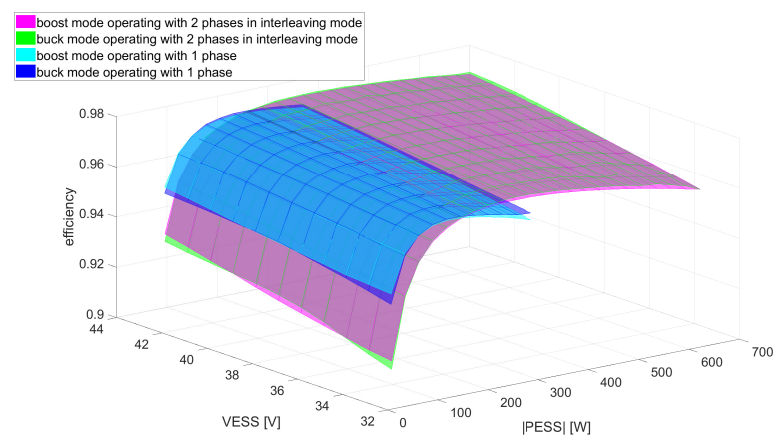

Fig. 3. Experimental efficiency for all the configurations of the MISB converter

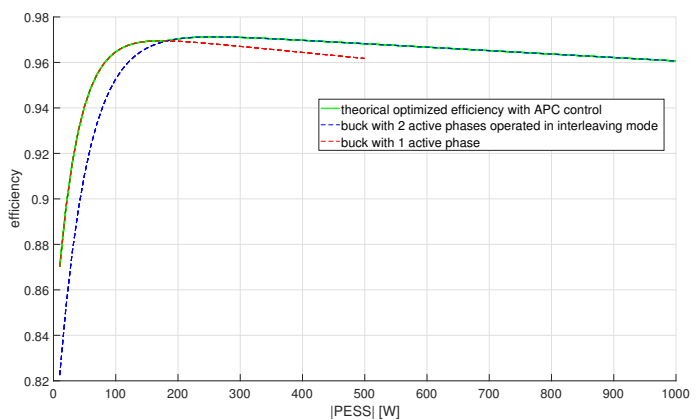

Fig. 4. Efficiency in buck operating mode with 1 or 2 phases, and optimal configuration when $\mathrm{V}_{\mathrm{ESS}}=32 \mathrm{~V}$

APC control. To carry out this analysis, we built a converter efficiency model in battery voltage and current ranges. In our case, the model is given by (1). We use an exponential expression depending on $P_{E S S}$ and with $f_{i}(i=1: 4)$ is a quadratic function depending on $\mathrm{V}_{\mathrm{ESS}}$.

$$
\begin{aligned}
\eta(t) & =f_{1}\left(V_{E S S}(t)\right) * \exp ^{f_{2}\left(V_{E S S}(t)\right) *\left|P_{E S S}(t)\right|} \\
& +f_{3}\left(V_{E S S}(t)\right) * \exp ^{f_{4}\left(V_{E S S}(t)\right) *\left|P_{E S S}(t)\right|}
\end{aligned}
$$

The measures presented in fig. 3 was used to identify the coefficients of our efficiency model. For a given number of active phases, we note a very small variation of the efficiency (less than 0.4\%) when the energy exchange direction changes. It can be due to the nature of the active components chosen with high efficiency and to the optimal switching frequency which was adapted to reduce losses. Nevertheless, we define four parameter sets dedicated to specific working conditions (number of phases activated and direction of the power exchange).

\section{RESUlTS}

A. Estimation of the impact of APC control for 5 years data set and lighting power profile

Fig. 5 compares the estimation of energy lost by days in our ISBC with and without APC control, during 5 years (2013 to 2017) and when the load connected to the LVDC bus is the building lighting network.

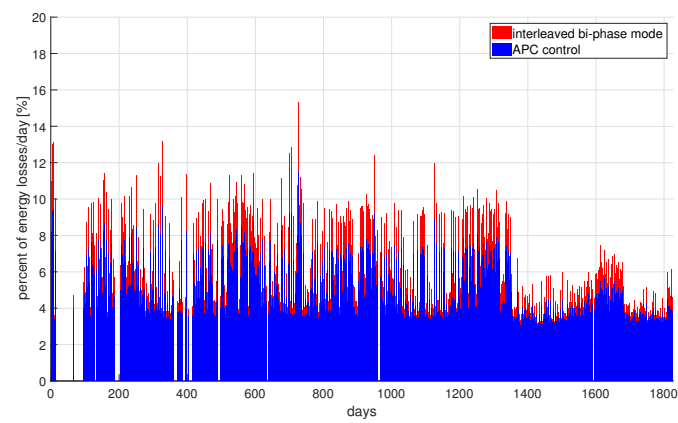

Fig. 5. Estimated ratio of the energy lost in the converter by the energy exchanged by day during 5 years

We can notice that some data are missing in this graphics. Indeed, data are unfortunately missing for 235 days if we combined PV production and lighting consumption data from 2013 to 2017 , i.e. about $13 \%$ of the days. Nevertheless, we estimate that this database is enough representative of changing weather and BiPV working conditions. In order to achieve a more significant analysis we calculate the total losses for 5 years with and without APC control. We estimated that $4.22 \%$ of the energy exchanged between the ESS and the DC bus was lost, if we used ISBC only in bi-phase mode to supply lighting network. When the APC control is implemented, we 
obtained in same working conditions an estimation of energy lost around $3.72 \%$, i.e. a decrease of $12 \%$ of the energy lost compared to the previous case.

To estimate the pertinence of APC control, it can be more interesting to estimate the level of energy saved. For that, we defined a ratio of the energy recovered thanks to APC control divided by the total energy transferred through the converter. Regarding the 5 years analysis, this ratio is equal to $0.5 \%$. We can converted the ratio of saved energy into the number of additional days available according to the average value of energy exchanged by day between the DC bus and the ESS. Considering this new metric, one week of energy can be recovered by implementing APC control in our ISBC. In case of self-sufficiency scenarios a week can be a significant time period.

Figure 6 presents the saved energy ratio by month. We can notice that this ratio is different from a month to an other. It increases between May and September (about $1.5 \%$ in August 2014) when the consumption of the lighting network decreases, which implies that the power exchanged with the ESS decreases and thus the advantage of APC control at low power is more significant. Indeed, as we can see in fig 7, there is a significant difference between the distributions of $\mathrm{P}_{\mathrm{ESS}}{ }^{*}$ between January and June.

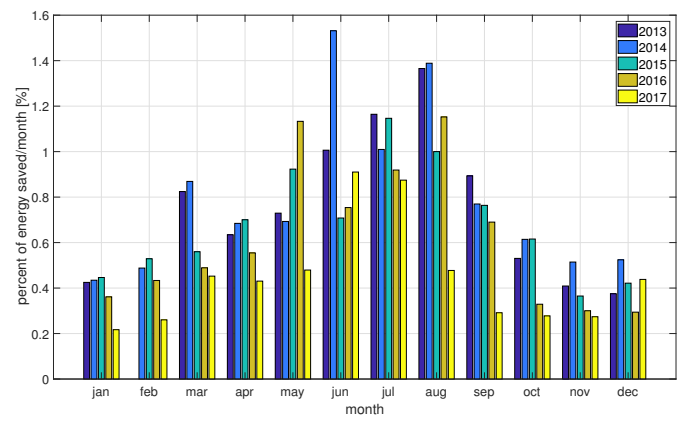

Fig. 6. Comparison between energy saved by month for 5 years

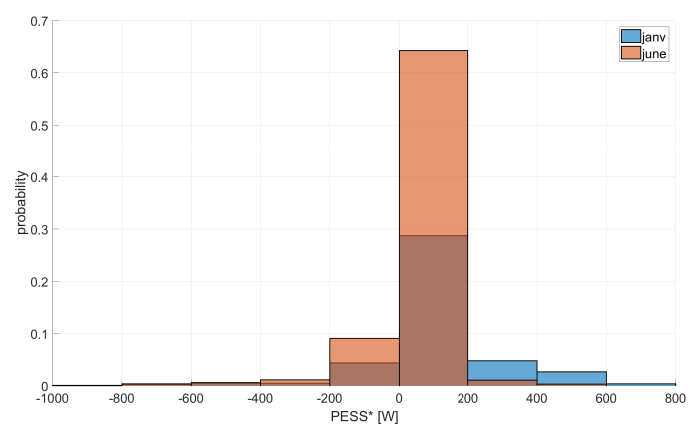

Fig. 7. Distribution of the power exchange between batteries and LVDC-MG in June and January for lighting power profile

\section{B. Load profile comparative study}

In order to evaluate the impact of APC control for an other load power profile we applied the same methodology on the power demand of tertiary building electrical outlets. Fig 8 represents the energy saved for one year simulation (2015) for the both profiles studied (lighting network and electrical outlets consumption).

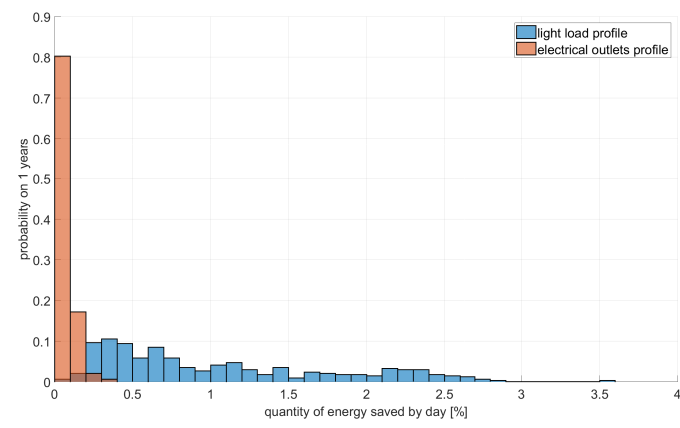

Fig. 8. Histogram of ratio of energy saved by day for lighting network and electrical outlets profile (2014)

In case of electrical outlets the saved energy ratio is less than $0.5 \%$ by day considering one year, while in the lighting network case, the saved energy ratio goes until $3.5 \%$ by day, and the distribution of $80 \%$ of the days are between 0 to $1,5 \%$. The results are similar if we compare the saved energy ratio by month for two different year, as we observe in fig 9. This is obviously the consequence of the different distribution of the two load profiles $\mathrm{P}_{\mathrm{ESS}}{ }^{*}$ as we can see in fig 10. In case of lighting network, a large range of operating point of $\mathrm{P}_{\mathrm{ESS}}{ }^{*}$ are in the interval (between -200W and 200W) where single phase mode is more efficient than bi-phase mode .

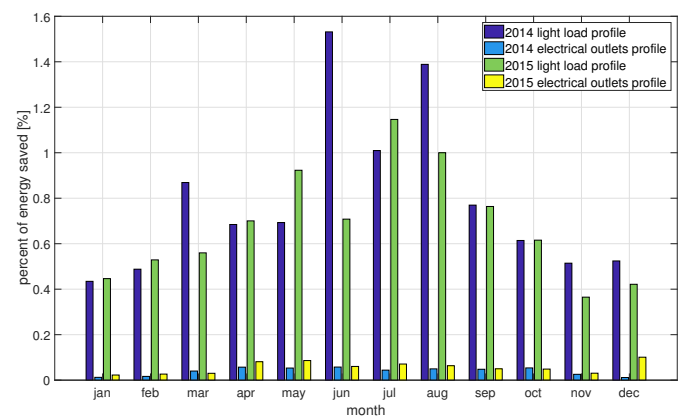

Fig. 9. Energy saved by month in percent for electrical outlets and lighting network load profile

All the results obtained are summarized in table II for the five years period.

\section{DisCusSiOnS}

The results presented above demonstrate the APC control benefits for system with PV production and power demand involving a frequent change between charge and discharge 
TABLE II

ESTIMATION OF THE LOSSES IN THE CONVERTER AND THE ENERGY SAVED FOR DIFFERENT TIME PERIOD FOR A DC LIGHTING NETWORK

\begin{tabular}{|c|c|c|c|c|c|c|}
\hline Horizon & losses without APC [\%] & losses with APC [\%] & looses reduction [\%] & energy saved ratio [\%] & $\begin{array}{c}\text { equivalent number of } \\
\text { days [days] }\end{array}$ \\
\hline 5 years & 4.22 & 3.72 & 12 & $0.5[0.01 ; 4.11]$ & 9 \\
\hline 2017 & 3.84 & 3.49 & 9 & 0.4 & $1^{1 / 2}$ \\
\hline 2016 & 4.18 & 3.7 & 11 & 0.5 & 2 \\
\hline 2015 & 4.43 & 3.88 & 12 & 0.6 & $2^{1 / 4}$ \\
\hline 2014 & 4.73 & 4.05 & 14 & 0.7 & $22^{1 / 2}$ \\
\hline 2013 & 4.53 & 3.96 & 13 & 0.6 & $1 / 4$ \\
\hline
\end{tabular}

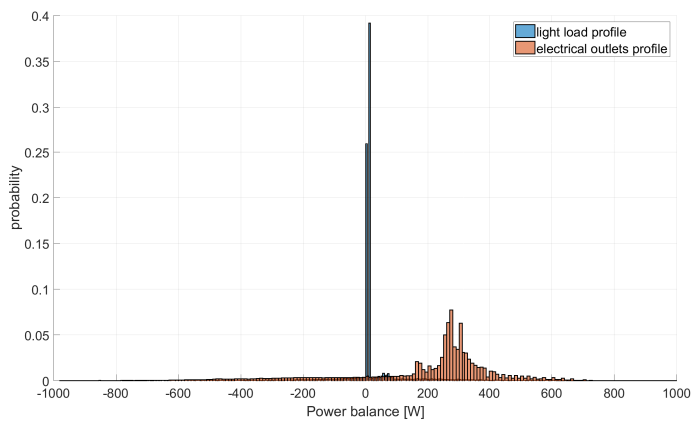

Fig. 10. Distribution of $\mathrm{P}_{\mathrm{ESS}}{ }^{*}$ for the two distinct load profiles: lighting network and electrical outlets for 2015

mode. In our case, APC control is interesting for the lighting network scenario when the range of the power exchanges between the ESS and the LVDC-MG is large, but the power is often in the low power interval. In contrary when the LVDCMG is dedicated to the electrical outlets, the main operating points of the $\mathrm{P}_{\mathrm{ESS}}{ }^{*}$ are out of the interval where single phase mode is more efficient than bi-phase mode and so the impact of the APC control on the global LVDC-MG efficiency is lower. One of the perspective to deal with this issue could be to work with multi-phase converter with more phases. But we have to consider that can increase the complexity of controls laws and global cost of the converters. According to [21] the converter efficiency increase for a larger range of operating points but adding components has a negative effect on reliability and influence the global cost.

An other point in favor of APC control is to improve the converter life time. Authors in [22] claim that adding APC control reduce the constraints on the electronics components and so extend the converter lifetime.

In our future work, we planed to add economical analysis considering number of components used, converter lifetime and reliability between single phase topology structure and ISBC converter with APC control.

\section{CONCLUSION}

This paper presented an analysis of the impacts of adding APC control on a ISBC efficiency which it is dedicated to ESS in LVDC-MG. This analysis is based on the efficiency model of the ISBC design in LAAS-CNRS, and real power profiles of lighting network demand, electrical outlets demand and the $\mathrm{PV}$ production in LAAS-CNRS BiPV.

The advantages of multi-phase interleaved power converters are well known, but the impact of APC control on the efficiency strongly depends on power profile. Based on 5 years power profiles of PV production and load consumption (lighting or electrical outlets), we shown that $12 \%$ of the energy lost in the converter is saved by the APC control when considering the lighting network. This represents $0.5 \%$ of the total energy exchanged between the battery and the LVDCMG, or 9 days according to the average value of the energy exchanged by day. A perspective of this study is to consider the life cycle cost and the reliability of the ISBC to quantify the APC control impact more precisely.

\section{REFERENCES}

[1] B. Zhong, X. Li, and Z. Zou, "Evaluating method of effectiveness of light energy's utilization based on service requirement," in Renewable Energy Research and Applications (ICRERA), 2015 International Conference on, pp. 246-251, IEEE, 2015.

[2] A. Thakur, L. Kumar, H. K. Romana, and R. K. Malik, "Energy Consumption Attributes in Residential Buildings- A Case Study of Replacing Conventional Electrical Appliances with Energy Efficient Appliances," International Journal of Renewable Energy Research (IJRER), vol. 7, pp. 1950-1955, Dec. 2017.

[3] A. Dolara, M. Longo, and M. Roscia, "Case study of light energy saving," in Renewable Energy Research and Applications (ICRERA), 2014 International Conference on, pp. 127-132, IEEE, Oct. 2014.

[4] "ADREAM project website https://www.laas.fr/public/fr/le-projetadream (2017-01-10)."

[5] J. Dulout, C. Alonso, L. Sguier, and B. Jammes, "Development of a photovoltaic low voltage DC microgrid for buildings with energy storage systems," in ELECTRIMACS 2017, vol. 2017, p. 6p, 2017.

[6] J. B. Copetti and F. Chenlo, "Lead/acid batteries for photovoltaic applications. Test results and modeling," Journal of power sources, vol. 47 , no. $1-2$, pp. 109-118, 1994.

[7] O. Tremblay and L.-A. Dessaint, "Experimental validation of a battery dynamic model for EV applications," World Electric Vehicle Journal, vol. 3, no. 1, pp. 1-10, 2009.

[8] H. He, R. Xiong, H. Guo, and S. Li, "Comparison study on the battery models used for the energy management of batteries in electric vehicles," Energy Conversion and Management, vol. 64, pp. 113-121, Dec. 2012.

[9] V. Prasad and B. P. Divakar, "Real Time Estimation of SOC and $\mathrm{SOH}$ of Batteries," International Journal of Renewable Energy Research (IJRER), vol. 8, pp. 44-55, Mar. 2018. 
[10] F. Sobrino-Manzanares and A. Garrigos, "Interleaved, multi-switch, multi phase boost converter for battery discharge regulators," in $E D P$ Sciences 2017, vol. 16, p. 6, E3S web of conferences 16, May 2017.

[11] R. Giral, L. Martinez-Salamero, and S. Singer, "Interleaved converters operation based on CMC," IEEE Transactions on Power Electronics, vol. 14 , no. 4, pp. 643-652, 1999.

[12] D. Schumacher, P. Magne, M. Preindl, B. Bilgin, and A. Emadi, "Closed loop control of a six phase interleaved bidirectional dc-dc boost converter for an EV/HEV application," in Transportation Electrification Conference and Expo (ITEC), 2016 IEEE, pp. 1-7, IEEE, 2016.

[13] A. Alzahrani, P. Shamsi, and M. Ferdowsi, "A novel interleaved nonisolated high-gain DC-DC boost converter with Greinacher voltage multiplier cells," in Renewable Energy Research and Applications (ICRERA), 2017 IEEE 6th International Conference on, pp. 222-227, IEEE, 2017.

[14] M. J. Ebrahimi and A. H. Viki, "Interleaved High Step-up DC-DC Converter with Diode-Capacitor Multiplier Cell and Ripple-Free Input Current," International Journal of Renewable Energy Research (IJRER), vol. 5, no. 3, pp. 782-788, 2015.

[15] S. Ganesan and V. Ramesh, "Performance improvement of micro grid energy management system using interleaved boost converter and $\mathrm{P} \& \mathrm{O}$ MPPT technique," International Journal of Renewable Energy Research (IJRER), vol. 6, no. 2, pp. 663-671, 2016.

[16] D. Radianto and M. Shoyama, "Neural network based a two phase interleaved boost converter for photovoltaic system," in Renewable Energy Research and Application (ICRERA), 2014 International Conference on, pp. 430-434, IEEE, 2014.

[17] R. B. Cunha, S. G. Di Santo, A. J. Sguarezi Filho, and F. F. Costa, "Finite control set applied to the current control of interleved boost converter of PV systems," in Renewable Energy Research and Applications (ICRERA), 2017 IEEE 6th International Conference on, pp. 580-584, IEEE, 2017

[18] L. Fleischli, S. Lemofouet, and A. Rufer, "Multichannel dc-dc converter's efficiency optimisation by variable number of active channels," in IEEE Industrial Electronics, IECON 2006-32nd Annual Conference on, pp. 2581-2586, IEEE, 2006.

[19] W. Qiu, C. Cheung, S. Xiao, and G. Miller, "Power loss analyses for dynamic phase number control in multiphase voltage regulators," in Applied Power Electronics Conference and Exposition, 2009. APEC 2009. Twenty-Fourth Annual IEEE, pp. 102-108, IEEE, 2009.

[20] A. Berasategi, C. Paragua, B. Estibals, Y. El Basri, L. Seguier, A. Ramond, C. Carrejo, and C. Alonso, "An adaptive control developed for Multi-Phase Converters based on look-up tables and applied to photovoltaic conversion systems," in IECON 2012-38th Annual Conference on IEEE Industrial Electronics Society, pp. 904-909, IEEE, 2012.

[21] S. Ramasamy, P. Abishri, and S. Umashankar, "Review of coupled two and three phase interleaved boost converter (IBC) and investigation of four phase IBC for renewable application," International Journal of Renewable Energy Research (IJRER), vol. 6, no. 2, pp. 421-434, 2016.

[22] A. Berasategi, Y. El Basri, C. Cabal, B. Estibals, M. Vermeersch, and C. Alonso, "Control laws to improve efficiency and average life time of an adaptive multi-phases converter dedicated to photovoltaic applications," in International Conference on Renewable Energies and Power Quality (ICREPQ'11), Las Palmas de Gran Canaria (Spain), pp. 13-15, 2011. 